\title{
A new screening tool for SARS-CoV-2 infection based on self-reported patient clinical characteristics: the $\mathrm{COV}_{19^{-}}$ID score
}

\author{
Pablo Diaz Badial ${ }^{1 \dagger}$, Hugo Bothore $^{2^{*}{ }^{\dagger}}$, Omar Kherad ${ }^{3}$, Philippe Dussoix ${ }^{1}$, Faustine Tallonneau Bory ${ }^{1}$ and \\ Majd Ramlawi ${ }^{1}$
}

\begin{abstract}
Background: While several studies aimed to identify risk factors for severe COVID-19 cases to better anticipate intensive care unit admissions, very few have been conducted on self-reported patient symptoms and characteristics, predictive of RT-PCR test positivity. We therefore aimed to identify those predictive factors and construct a predictive score for the screening of patients at admission.

Methods: This was a monocentric retrospective analysis of clinical data from 9081 patients tested for SARS-CoV-2 infection from August 1 to November 30 2020. A multivariable logistic regression using least absolute shrinkage and selection operator (LASSO) was performed on a training dataset (60\% of the data) to determine associations between self-reported patient characteristics and COVID-19 diagnosis. Regression coefficients were used to construct the Coronavirus 2019 Identification score (COV 19 -ID) and the optimal threshold calculated on the validation dataset (20\%). Its predictive performance was finally evaluated on a test dataset (20\%).
\end{abstract}

Results: A total of 2084 (22.9\%) patients were tested positive to SARS-CoV-2 infection. Using the LASSO model, COVID-19 was independently associated with loss of smell (Odds Ratio, 6.4), fever (OR, 2.7), history of contact with an infected person $(O R, 1.7)$, loss of taste $(O R, 1.5)$, muscle stiffness $(O R, 1.5)$, cough $(O R, 1.5)$, back pain $(O R, 1.4)$, loss of appetite (OR, 1.3), as well as male sex (OR, 1.05). Conversely, COVID-19 was less likely associated with smoking (OR, $0.5)$, sore throat $(\mathrm{OR}, 0.9)$ and ear pain $(\mathrm{OR}, 0.9)$. All aforementioned variables were included in the $\mathrm{COV}_{19}-\mathrm{ID}$ score, which demonstrated on the test dataset an area under the receiver-operating characteristic curve of $82.9 \%(95 \% \mathrm{Cl}$ $80.6 \%-84.9 \%)$, and an accuracy of $74.2 \%$ (95\% Cl 74.1\%-74.3\%) with a high sensitivity (80.4\%, 95\% Cl [80.3\%-80.6\%]) and specificity $(72.2 \%, 95 \% \mathrm{Cl}[72.2 \%-72.4 \%])$.

Conclusions: The $\mathrm{COV}_{19}-\mathrm{ID}$ score could be useful in early triage of patients needing RT-PCR testing thus alleviating the burden on laboratories, emergency rooms, and wards.

Keywords: COVID-19, SARS-CoV-2, Screening, Triage, Predictive score, Self-reported symptoms, Machine learning, Artificial Intelligence

*Correspondence: hugo.bothorel@latour.ch

${ }^{\dagger}$ Pablo Diaz Badial and Hugo Bothorel contributed equally to this work

${ }^{2}$ Research Department, La Tour Hospital, 1217 Geneva, Switzerland

Full list of author information is available at the end of the article

\section{Background}

The current Coronavirus Disease 2019 (COVID-19) pandemic, represents one of the greatest medical challenges that the world had to face since decades. As COVID19 quickly spread, various nonspecific clinical signs and symptoms have been reported making COVID-19 
hard to differentiate from a broad range of respiratory tract infections [1, 2]. Diagnostic testing using realtime reverse transcription polymerase chain reaction (RT-PCR) has therefore been used to identify infected patients $[3,4]$ Several studies aimed to identify risk factors for severe acute respiratory syndrome coronavirus 2 (SARS-CoV-2) infection severity in order to anticipate intensive care unit (ICU) admissions [5-25].

However, few studies have been conducted on selfreported patient symptoms and characteristics, predictive of RT-PCR test positivity [4, 26-29]. Models involving loss of smell, loss of taste, cough and fever have been shown to reveal a higher infection likelihood [30, 31]. Although these predictive models were built on large cohorts, the proportion of infected patients was largely overestimated and symptoms may not have been collected with precision at the time of RT-PCR testing.

The main purpose of the present study was to identify predictive factors for SARS-CoV-2 infection based on self-reported patient symptoms and medical conditions, and construct a predictive score for patient screening at admission. Given the lack of availability of RT-PCR testing and delay in results, a reliable and quick tool may help clinicians on the front line in the prioritization for screening of patients at high risk for SARS-COV-2 infection.

\section{Methods}

Study design and participants

A retrospective analysis of clinical data from 10,527 consecutive patients tested for SARS-CoV-2 infection was undertaken at the La Tour Hospital's emergency center in Geneva (Switzerland) between the 1st of August and the 30th of November 2020. Our emergency department is an academically affiliated teaching center, requisitioned for SARS-COV-2 testing by the city's health authorities. It represents the 2nd largest emergency in the city, accounting for 29,000 visits per year. All RT-PCR tests performed on patients younger than 18 years of age ( $n=881,7.9 \%$ ) were excluded (Fig. 1). Since RT-PCR tests are associated with a variable false-negative rate [32], we excluded all non-final results from patients tested several times in our hospital due to worsening symptoms $(\mathrm{n}=530,4.8 \%)$. All incomplete forms were also excluded $(\mathrm{n}=595,5.4 \%)$. Ultimately, this led to the remainder of 9081 patients comprising 6871 symptomatic $(75.7 \%)$ and 2210 asymptomatic $(24.3 \%)$ cases with a unique final RTPCR result for further analyses. Asymptomatic patients were tested for travelling purposes $(n=834,9.2 \%)$,

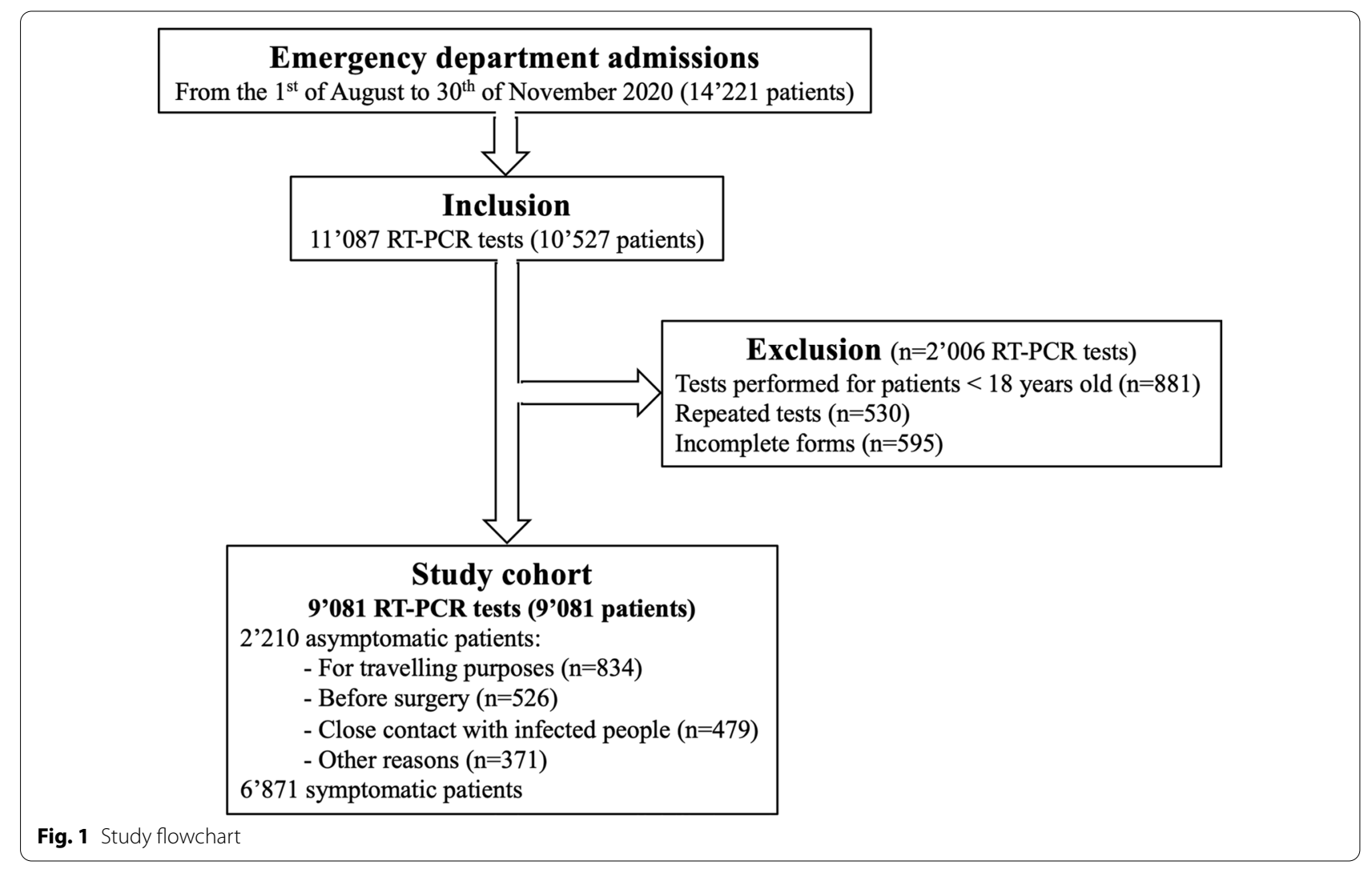


before surgery $(\mathrm{n}=526,5.8 \%)$, following a close contact with infected people $(n=479,5.3 \%)$ or for other reasons $(\mathrm{n}=371,4.1 \%)$. This study was approved by the ethics committee of Geneva (CCER 2020-01742) and the need for informed written consent was waived owing to the urgent situation and the retrospective use of anonymized data.

\section{RT-PCR tests}

SARS-CoV-2 infection was confirmed by positive RT-PCR tests on nasopharyngeal swab specimens. Specimens were sent to and analyzed by the National Reference Center for Emergency Viral Infections (CRIVE) at the Geneva University Hospital (HUG). PCR assays were performed using the Roche's cobas ${ }^{\circledR} 6800$ SARS-CoV-2 analyzer (Roche Molecular Systems, Branchburg, NJ) which received CE certification and the Emergency Use Authorization (EUA) by the U.S. Food and Drug Administration (FDA).

\section{Study variables}

Each enlisted patient, filled a case report form (CRF) at the time of screening. The study variables included demographic data (age, gender, weight, height, profession) and a series of specific symptoms including cough, breathing difficulties, runny nose, sore throat, ear pain, headache, fever, muscle stiffness, back pain, diarrhea, nausea/vomiting, loss of appetite, loss of weight, loss of smell, loss of taste, dizziness, respiratory allergies and unusual fatigue. Other potential risk factors recorded included immunosuppression, diabetes, tobacco use, chronic pulmonary and heart disease, cancer as well as any history of close contact with people who have tested positive for SARSCoV-2 infection. The data was then imported in a digital database, coded for anonymization, and stored on a secured hospital server.

\section{Statistical analyses}

For baseline characteristics, continuous variables were reported as mean \pm standard deviation with median and interquartile range (IQR), while categorical variables were reported as proportions. For non-Gaussian continuous data, differences between groups were evaluated using Wilcoxon rank-sum tests (Mann-Whitney U test), while for Gaussian continuous data, differences between groups were evaluated using unpaired Student t-tests. For categorical data, differences between groups were evaluated using the Fisher exact test. Univariable and multivariable logistic regressions were performed to determine associations between self-reported patient characteristics and COVID-19 diagnosis. Authors did not use imputation methods and performed their analyses on existing and complete data, thus the presented screening tool could only be used when information about all patient symptoms and characteristics is known. Sixty percent of the study population was randomly selected and contributed to build the multivariable logistic model (60\%, training dataset), while the remaining part was kept to validate (20\%, validation dataset) and test the model ( $20 \%$, test dataset). The variables included in the shortened multivariable regression model were identified using the least absolute shrinkage and selection operator (LASSO) method. The regularization parameter used in this method was determined using a tenfold cross-validation, and set at one standard error from the $\lambda$ that minimizes classification error $(\lambda .1 \mathrm{se})$. Collinearity was assessed using the Variance Inflation Factor (VIF) for each covariate, and was deemed acceptable if the maximum VIF did not exceed 2.0. Odds ratios (OR) and the 95\% CI were calculated for each independent variable. Probability of being infected by SARS-CoV-2 was calculated as follows:

$$
\text { Infection probability }=\frac{1}{1+\mathrm{e}^{-(\text {Intercept }+\beta 1 \mathrm{X} 1+\beta 2 \mathrm{X} 2+\ldots+\beta n \mathrm{Xn})}}
$$

With "Intercept" being the regression model intercept, and $\beta$ the regression coefficient related to the independent variable $X(X=0$ or 1$)$. The regression coefficient for each independent variable selected in the multivariable model was multiplied by ten, rounded up to the nearest integer value, and used to build a predictive score: The Coronavirus 2019 Identification $\left(\mathrm{COV}_{19}\right.$-ID) score. The regression coefficients were thereafter adjusted proportionally to set the maximum of the score at 100 . The Receiver operating characteristic (ROC) curve was constructed and its area under the curve (AUC) evaluated. The optimal cutoff value was then calculated on the validation dataset to discriminate between infected patients and non-infected patients with the highest sensitivity and specificity (Youden Index). Two other thresholds were additionally described in a Additional file 1 to maximize either the sensitivity or the specificity of the $\mathrm{COV}_{19}$-ID score. To validate the variable selection in the LASSO regression, the AUCs obtained by the $\mathrm{COV}_{19}$-ID score and the entire multivariable model were evaluated and compared using a paired DeLong test. The sensitivity, specificity, positive and negative predictive values (PPV and NPV), positive and negative likelihood ratio (LR+ and LR-), F1 score and the Matthews correlation coefficient (MCC) were calculated on the test dataset based on the number of true positive (TP), false negative (FN), false positive (FP) and true negative (TN) cases. A bootstrap method with 1000 random resamples of the test dataset was used to calculate the $95 \%$ confidence interval $(95 \% \mathrm{CI})$ of all aforementioned parameters. 
Statistical analyses were performed using $\mathrm{R}$ version 3.6.2 (R Foundation for Statistical Computing, Vienna, Austria). P-values $<0.05$ were considered statistically significant.

\section{Results}

A total of 14,221 patients were admitted to the emergency department from the 1st of August through the 30th of November 2020. 10,527 (74.0\%) were tested for SARS-CoV-2 infection using RT-PCR tests, among whom 9081 were further analyzed (Fig. 1). The studied cohort included 4280 men (47\%) with a mean age of $43.5 \pm 15.6$ years and a mean BMI of $25.1 \pm 4.8 \mathrm{~kg} / \mathrm{m}^{2}$. The most common reported symptoms were headache $(38.6 \%)$, cough $(38.4 \%)$, runny nose $(34.0 \%)$, sore throat (31.4\%), unusual fatigue (30.4\%), muscle stiffness (27.3\%) and back pain (22.4\%) (Table 1).

\section{Predictive factors of SARS-CoV-2 infection}

Among the tested population included in this study, 2084 patients $(22.9 \%)$ were diagnosed with SARS-CoV-2 infection. Compared to patients with negative test

Table 1 Patient characteristics for the entire cohort and by RT-PCR result subgroup (categorical data)

\begin{tabular}{|c|c|c|c|c|}
\hline & $\begin{array}{l}\text { Total }(n=9081) \\
N(\%)\end{array}$ & $\begin{array}{l}\text { Positive }(n=2084) \\
N(\%)\end{array}$ & $\begin{array}{l}\text { Negative }(n=6997) \\
N(\%)\end{array}$ & $p$-value \\
\hline Symptomatic & $6871(75.7)$ & $1993(95.6)$ & $4878(69.7)$ & $<0.001$ \\
\hline Age (yrs) & & & & 0.185 \\
\hline $18-39$ & $3961(43.6)$ & $867(41.6)$ & $3094(44.2)$ & \\
\hline $40-64$ & $4226(46.5)$ & $1011(48.5)$ & $3215(46.0)$ & \\
\hline $65-74$ & $554(6.1)$ & $127(6.1)$ & $427(6.1)$ & \\
\hline$\geq 75$ & $340(3.7)$ & $79(3.8)$ & $261(3.7)$ & \\
\hline Male sex & $4280(47.1)$ & $1049(50.3)$ & $3231(46.2)$ & $<0.001$ \\
\hline Cough & $3489(38.4)$ & $1105(53.0)$ & $2384(34.1)$ & $<0.001$ \\
\hline Contact ${ }^{a}$ COVID-19+ & $3179(35.0)$ & $1004(48.2)$ & $2175(31.1)$ & $<0.001$ \\
\hline Breathing difficulties & $1034(11.4)$ & $281(13.5)$ & $753(10.8)$ & 0.001 \\
\hline Runny nose & $3087(34.0)$ & $870(41.7)$ & $2217(31.7)$ & $<0.001$ \\
\hline Sore throat & $2850(31.4)$ & $629(30.2)$ & $2221(31.7)$ & $<0.001$ \\
\hline Ear pain & $546(6.0)$ & $123(5.9 \%)$ & $423(6.0)$ & 0.834 \\
\hline Headache & $3502(38.6)$ & $1080(51.8)$ & $2422(34.6)$ & $<0.001$ \\
\hline Fever & $1246(13.7)$ & $584(28.0)$ & $662(9.5)$ & $<0.001$ \\
\hline Diarrhea & $1000(11.0)$ & $261(12.5)$ & 739 (10.6) & 0.013 \\
\hline Nausea & 787 (8.7) & $210(10.0)$ & $577(8.2)$ & 0.010 \\
\hline Loss of smell & $754(8.3)$ & $529(25.4)$ & $225(3.1)$ & $<0.001$ \\
\hline Loss of taste & $715(7.9)$ & $466(22.4)$ & 249 (3.6) & $<0.001$ \\
\hline Diabetes & $289(3.2)$ & $76(3.6)$ & $213(3.0)$ & 0.177 \\
\hline Immunosuppression & $92(1.0)$ & $15(0.7)$ & $77(1.1)$ & 0.136 \\
\hline Chronic pulmonary disease & $149(1.6)$ & $32(1.5)$ & $117(1.7)$ & 0.768 \\
\hline Chronic heart disease & $221(2.4)$ & $51(2.4)$ & $170(2.4)$ & 0.936 \\
\hline Cancer & $226(2.5)$ & $46(2.2)$ & $180(2.6)$ & 0.379 \\
\hline Healthcare worker & $409(4.5)$ & $93(4.5)$ & $316(4.5)$ & 0.952 \\
\hline Respiratory allergies & $1121(12.3)$ & $247(11.8)$ & $874(12.5)$ & 0.448 \\
\hline Smoking & $1408(15.5)$ & $208(10.0)$ & $1200(17.2)$ & $<0.001$ \\
\hline Unusual fatigue & $2762(30.4)$ & $845(40.5)$ & $1917(27.4)$ & $<0.001$ \\
\hline Obesity (BMI>30) & $1212(13.3)$ & $286(13.7)$ & $926(13.2)$ & 0.557 \\
\hline Muscle stiffness & $2481(27.3)$ & $936(44.9)$ & $1545(22.1)$ & $<0.001$ \\
\hline Back pain & $2031(22.4)$ & $784(37.6)$ & $1247(17.8)$ & $<0.001$ \\
\hline Loss of appetite & $930(10.2)$ & $410(19.7)$ & $520(7.4)$ & $<0.001$ \\
\hline Loss of weight & $160(1.8)$ & $78(3.7)$ & $82(1.2)$ & $<0.001$ \\
\hline Dizziness & $651(7.2)$ & $206(9.9)$ & $445(6.4)$ & $<0.001$ \\
\hline
\end{tabular}

Italic values indicate significant $p$-values $(<0.05)$

${ }^{a}$ Close contact with people who have tested positive for SARS-CoV-2 infection 
results $(n=6997,77.1 \%)$, confirmed cases were more likely of male sex $(50.3 \%$ vs $46.2 \%)$ and symptomatic (95.6\% vs $69.7 \%$ ) (Table 1 ). The differences in terms of age $(44.2 \pm 15.6$ vs. $43.3 \pm 15.5$ years, $\mathrm{p}<0.001)$, BMI $\left(25.4 \pm 4.8\right.$ vs. $\left.25.0 \pm 4.8 \mathrm{~kg} / \mathrm{m}^{2}, \mathrm{p}<0.001\right)$, and time since symptoms onset $(4.0 \pm 6.0$ vs $4.2 \pm 5.0$ days, $\mathrm{p}<0.001)$ were statistically significant but not clinically relevant. Main symptoms reported by the infected group included loss of smell $(25.4 \%$ vs $3.1 \%$; $p<0.001)$, loss of taste $(22.4 \%$ vs $3.6 \%$; $\mathrm{p}<0.001)$, fever $(28.0 \%$ vs $9.5 \%$; $\mathrm{p}<0.001)$, muscle stiffness $(44.9 \%$ vs $22.1 \%$; $p<0.001)$, back pain $(37.6 \%$ vs $17.8 \% ; \mathrm{p}<0.001)$ and loss of appetite $(19.7 \%$ vs $7.4 \%)$ (Table 1).

\section{Full multivariable model}

SARS-CoV-2 infection was independently associated with loss of smell (OR, 9.4; 95\% CI 6.9-12.8), fever (OR, 3.4; 95\% CI, 2.8-4.1), increasing age (e.g. $\geq 75$ y.o. vs. 18-39 y.o.: OR, 2.4; 95\% CI 1.6-3.6), history of contact with an infected person (OR, 2.3; 95\% CI 2.0-2.7), cough (OR, 2.1; 95\% CI 1.8-2.5]), loss of taste (OR, 2.0; 95\% CI 1.4-2.7), back pain (OR, 1.8; 95\% CI 1.5-2.2), loss of appetite (OR, 1.8; 95\% CI 1.4-2.3), muscle stiffness (OR, 1.7; 95\% CI 1.5-2.1), as well as male sex (OR, 1.3; 95\% CI 1.1-1.5) and headache (OR, 1.3; 95\% CI 1.1-1.5). Conversely, COVID-19 was less likely associated with smoking (OR, 0.3; 95\% CI 0.2-0.4), immunosuppression (OR, 0.3 ; 95\% CI 0.1-0.7), ear pain (OR, 0.6; 95\% CI 0.4-0.8), sore throat (OR, $0.7 ; 95 \% \mathrm{CI} 0.6-0.9)$ and breathing difficulties (OR, 0.7; 95\% CI 0.6-0.9) (Table 2).

\section{Creation and validation of the $\mathrm{COV}_{19}-\mathrm{ID}$ score}

Only twelve of the aforementioned predictors of SARS$\mathrm{CoV}-2$ infection were selected by the LASSO regression and used to create the $\mathrm{COV}_{19}$-ID score (Fig. 2 and 3). The $\mathrm{COV}_{19}$-ID score was thereafter calculated for all patients comprised in the validation dataset, which included 407 (22.5\%) positive and 1399 (77.5\%) negative cases.

On the validation dataset, the mean $\mathrm{COV}_{19}$-ID score was 10.0 \pm 13.7 (median, 8.0; IQR, $0.0-16.0$ ) for patients with negative RT-PCR and $29.0 \pm 20.9$ (median, 25.0; IQR, 14.0-41.0) for patients with positive RT-PCR. The AUC obtained with the $\mathrm{COV}_{19}$-ID score was not significantly different from the AUC obtained with the full multivariable model (79.1\% vs $79.8 \%, \mathrm{p}=0.121$ ) (Fig. 4).

The $\mathrm{COV}_{19}$-ID score accuracy was $72.4 \%$ when maximizing both the sensitivity and specificity (cutoff value of $\geq 14$ points). The sensitivity and specificity were $75.4 \%$ and $71.5 \%$ respectively, with a PPV of $43.5 \%$ and an NPV of $90.9 \%$ (Table 3 ). The F1 score and MCC were 0.55 and 0.40 respectively. Two other $\mathrm{COV}_{19}$-ID score thresholds were calculated to maximize either the sensitivity $(\geq 8.5$ points) or the specificity ( $\geq 25$ points).

\section{Test of the $\mathrm{COV}_{19}$-ID score}

Using the test dataset, which comprised 429 (23.6\%) positive cases and 1386 (76.4\%) negative cases, the AUC obtained with the $\mathrm{COV}_{19}$-ID score was $82.9 \%$ (95\% CI $80.6 \%-84.9 \%)$. Using the cutoff value of $\geq 14$ points, the accuracy was of $74.2 \%$ (95\% CI $74.1 \%-74.3 \%)$ with a sensitivity and specificity of $80.4 \%$ (95\% CI $80.4 \%-80.6 \%$ ) and $72.2 \%$ (95\% CI $72.2 \%-72.3 \%)$ respectively. The PPV was $47.3 \%$ (95\% CI $47.2 \%-47.4 \%$ ) and the NPV of $92.3 \%$ (95\% CI 92.3\%-92.4\%) (Table 3). The F1 score and MCC were 0.60 (95\% CI $0.59-0.60)$ and $0.46(0.45-0.46)$ respectively. The comparison between the predicted probabilities of SARS-COV-2 infection and the RT-PCR test results is illustrated in Additional file 1. The model diagnostic performance using the three different thresholds is illustrated on Fig. 5 and detailed in Additional file 2 .

\section{Discussion}

The rapid spread of the COVID-19 pandemic and the need for mass testing invariably overwhelms laboratory capabilities resulting in increased result delays. To date, proposed screening tools [33, 34] mainly concern the detection of severe cases in order to anticipate for ICU admissions [5-25]. However, screening for SARS-CoV-2 infection at admission, may help discriminate between highly suspected patients needing quarantine measures or admission to COVID-19 dedicated units from those who could safely be discharged [35], while test results are pending. Our study presented and validated a new clinical tool $\left(\mathrm{COV}_{19}\right.$-ID score) for SARS-CoV-2 infection based on the patient's self-reported symptoms and medical history.

With an AUC of $83 \%$, a sensitivity of $80 \%$ and a specificity of $72 \%$ for the prediction of SARS-CoV-2 infection in our test dataset, our screening tool compares well with the model of Menni et al. [31] who reported an AUC of $76 \%$ (sensitivity, 65\%; specificity, $78 \%$ ) in a United States cohort with a comparable proportion of infected patients ( $26 \%$ vs $24 \%$ in our test dataset). In their study, Zavascki et al. [36] created a score which included only 5 variables (patient age $\geq 60$ years old, fever, dyspnea, coryza, and fatigue) that demonstrated an AUC of $88 \%$ in their validation dataset. It is worth noting however, that they did not use an external database for the validation process and that important symptoms such as loss of taste and loss of smell were not reported and incorporated in their model. In our study, $47 \%$ of the patients predicted of being infected by SARS-COV-2, truly had a positive test. This PPV is lower than that reported by Menni et al. [31] (69\%). On the other hand, $92 \%$ of the patients predicted as not being infected had a negative test which is higher 
Table 2 Uni- and Multivariable logistic regression of positive RT-PCR test (training data)

\begin{tabular}{|c|c|c|c|c|c|c|}
\hline \multirow[t]{3}{*}{ Variable } & \multicolumn{2}{|c|}{ Univariable regression } & \multicolumn{4}{|c|}{ Multivariable regression } \\
\hline & \multirow[b]{2}{*}{ OR (95\% C.I.) } & \multirow[b]{2}{*}{$p$-value } & \multicolumn{2}{|l|}{ Full model } & \multicolumn{2}{|c|}{ LASSO model } \\
\hline & & & OR (95\% C.I.) & p-value & Coeff & OR \\
\hline \multicolumn{7}{|l|}{ Age group } \\
\hline $18-39$ & Ref. & & Ref. & & & \\
\hline $40-64$ & $1.1(0.9-1.2)$ & 0.440 & $1.3(1.1-1.6)$ & $<0.001$ & & \\
\hline $65-74$ & $1.1(0.8-1.4)$ & 0.719 & $1.7(1.3-2.4)$ & $<0.001$ & & \\
\hline$\geq 75$ & $1.3(0.9-1.7)$ & 0.175 & $2.4(1.6-3.6)$ & $<0.001$ & & \\
\hline Male sex & $1.2(1.1-1.4)$ & 0.006 & $1.3(1.1-1.5)$ & $<0.001$ & 0.035 & 1.05 \\
\hline Cough & $2.2(1.9-2.5)$ & $<0.001$ & $2.1(1.8-2.5)$ & $<0.001$ & 0.437 & 1.5 \\
\hline Contact $^{\mathrm{a}}$ COVID-19+ & $2.1(1.8-2.3)$ & $<0.001$ & $2.3(2.0-2.7)$ & $<0.001$ & 0.546 & 1.7 \\
\hline Breathing difficulties & $1.3(1.1-1.6)$ & 0.002 & $0.7(0.6-0.9)$ & 0.012 & & \\
\hline Runny nose & $1.5(1.3-1.7)$ & $<0.001$ & $1.1(0.9-1.3)$ & 0.175 & & \\
\hline Sore throat & $1.0(0.8-1.1)$ & 0.641 & $0.7(0.6-0.8)$ & $<0.001$ & -0.108 & 0.9 \\
\hline Ear pain & $0.9(0.7-1.2)$ & 0.530 & $0.6(0.4-0.8)$ & 0.002 & -0.098 & 0.9 \\
\hline Headache & $2.0(1.7-2.2)$ & $<0.001$ & $1.3(1.1-1.5)$ & 0.003 & & \\
\hline Fever & $3.8(3.2-4.4)$ & $<0.001$ & $3.4(2.8-4.1)$ & $<0.001$ & 1.004 & 2.7 \\
\hline Diarrhea & $1.3(1.0-1.5)$ & 0.021 & $0.8(0.7-1.1)$ & 0.173 & & \\
\hline Nausea & $1.3(1.0-1.6)$ & 0.031 & $0.8(0.6-1.0)$ & 0.109 & & \\
\hline Loss of smell & 11.0 (8.9-13.6) & $<0.001$ & $9.4(6.9-12.8)$ & $<0.001$ & 1.857 & 6.4 \\
\hline Loss of taste & $7.5(6.1-9.2)$ & $<0.001$ & $2.0(1.4-2.7)$ & $<0.001$ & 0.432 & 1.5 \\
\hline Diabetes & $1.3(0.9-1.8)$ & 0.144 & $1.2(0.8-1.8)$ & 0.312 & & \\
\hline Immunosuppression & $0.4(0.2-0.9)$ & 0.045 & $0.3(0.1-0.7)$ & 0.010 & & \\
\hline Chronic pulmonary disease & $0.9(0.5-1.5)$ & 0.754 & $0.7(0.4-1.3)$ & 0.322 & & \\
\hline Chronic heart disease & $0.8(0.5-1.3)$ & 0.415 & $0.6(0.3-1.0)$ & 0.055 & & \\
\hline Cancer & $0.8(0.5-1.3)$ & 0.380 & $0.9(0.5-1.5)$ & 0.665 & & \\
\hline Healthcare worker & $1.0(0.7-1.3)$ & 0.932 & $0.8(0.6-1.2)$ & 0.306 & & \\
\hline Respiratory allergies & $0.9(0.7-1.1)$ & 0.186 & $0.9(0.7-1.1)$ & 0.408 & & \\
\hline Smoking & $0.5(0.4-0.6)$ & $<0.001$ & $0.3(0.2-0.4)$ & $<0.001$ & -0.672 & 0.5 \\
\hline Unusual fatigue & $1.7(1.5-1.9)$ & $<0.001$ & $0.9(0.8-1.1)$ & 0.237 & & \\
\hline Obesity & $1.1(0.9-1.3)$ & 0.368 & $1.0(0.8-1.2)$ & 0.651 & & \\
\hline Muscle stiffness & $2.6(2.3-3.0)$ & $<0.001$ & $1.7(1.5-2.1)$ & $<0.001$ & 0.390 & 1.5 \\
\hline Back pain & $2.6(2.2-2.9)$ & $<0.001$ & $1.8(1.5-2.2)$ & $<0.001$ & 0.335 & 1.4 \\
\hline Loss of appetite & $3.1(2.6-3.7)$ & $<0.001$ & $1.8(1.4-2.3)$ & $<0.001$ & 0.275 & 1.3 \\
\hline Loss of weight & $2.9(2.0-4.4)$ & $<0.001$ & $1.2(0.7-1.9)$ & 0.554 & & \\
\hline Dizziness & $1.7(1.3-2.1)$ & $<0.001$ & $1.0(0.8-1.4)$ & 0.744 & & \\
\hline
\end{tabular}

Italic values indicate significant $p$-values $(<0.05)$

Multivariable model intercept: -2.153

OR, Odds ratio; $\mathrm{Cl}$, Confidence Interval; Coeff, coefficient

${ }^{a}$ Close contact with people who have tested positive for SARS-CoV-2 infection

than that reported in the above study [31] (75\%). These comparisons, however, should be interpreted with caution considering the differences in the studied population (e.g. the proportion of infected cases) and the cut-off value chosen for the prediction.

Main symptoms reported by COVID-19 patients included loss of smell, loss of taste, fever, muscle stiffness, back pain and loss of appetite. Known as a risk factor for transmission of the disease, exposure to a contagious person was only found in less than half of infected patients. This emphasizes the role of asymptomatic viral transmission in the population and the need for enhanced compliance with barrier measures. Although breathing difficulties has been largely described as one of the most prevalent symptoms associated with COVID-19 [37], our study revealed that in absence of cofounding factors, 


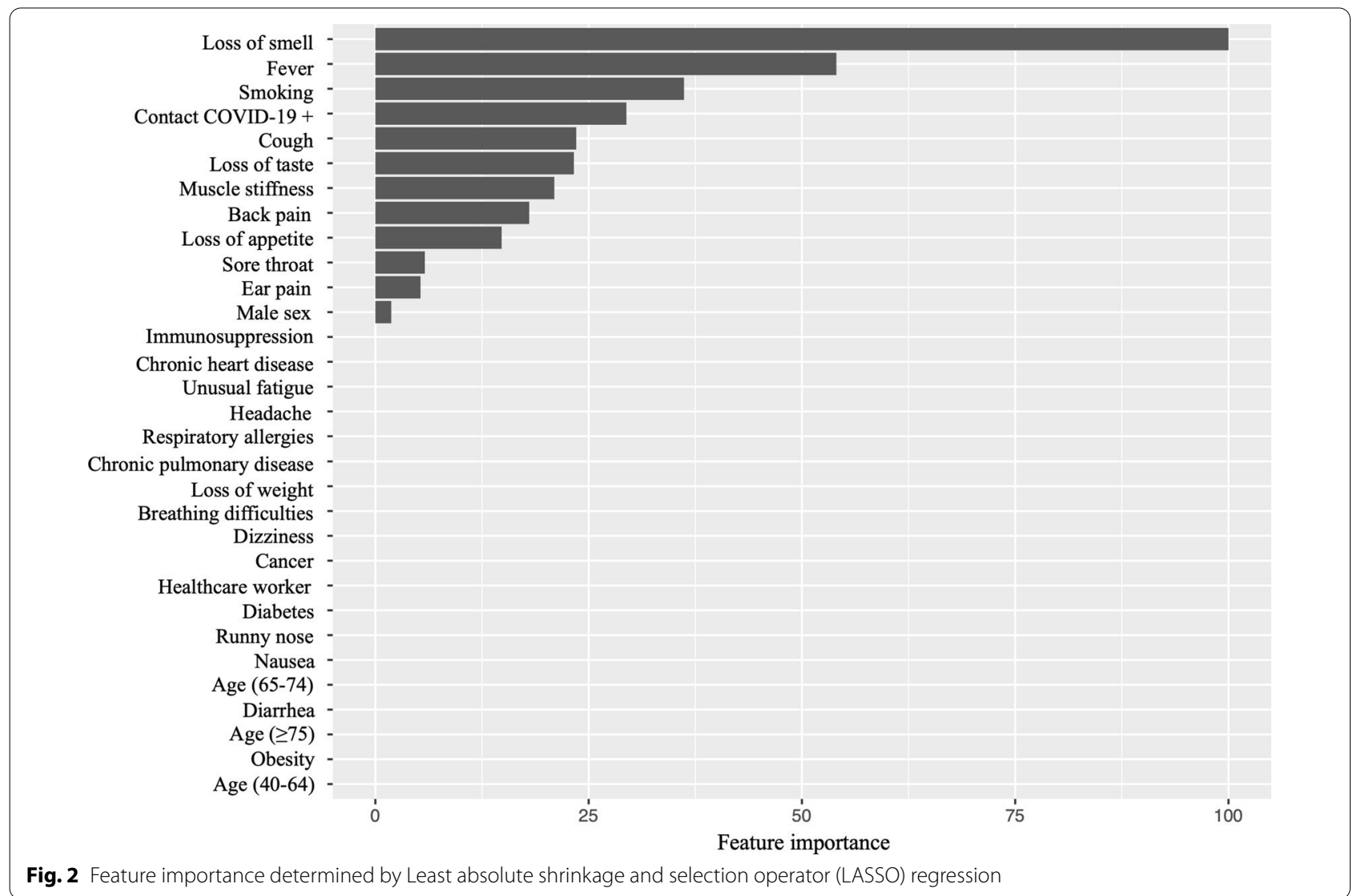

this symptom was rather suggestive of a non-SARS$\mathrm{CoV}-2$ infection. This finding was contradictory with those of Romero-Gameros et al. [38] but corroborated several recent studies that described a possible association between SARS-CoV-2 infection and lack of dyspnea (silent hypoxia) due to neurological damages [39, 40]. Another explanation would be that patients who did not present clinical signs suggestive of COVID-19, reported dyspnea because of other type of pneumonia or simply stress/anxiety before RT-PCR testing. Patients with sore throat and/or ear pain were also less likely to be infected by SARS-CoV-2, suggesting that these symptoms are more specific to other ears, nose and throat (ENT) diseases. Likewise, Spechbach et al. reported breathing difficulties and sore throat as predictors of a negative RT-PCR test [41]. Recent studies indicated that smokers tended to be less infected $[4,30,42]$. Our results corroborate these findings given that the odds of SARS-CoV-2 infection was two times less important for smokers.

Twelve variables were selected for the construct of the $\mathrm{COV}_{19}$-ID score owing to their high independent explanatory effect on SARS-CoV-2 infection. Among them, nine were potent risk factors for infection; comprising male sex, cough, loss of smell, loss of taste, fever, muscle stiffness, back pain, loss of appetite, and history of close contact with infected people. Our results are very similar to those published by Spechbach et al. who found that anosmia, fever, muscle pain, and cough were strong COVID-19 predictors [41]. In Menni et al.s prediction model [31], loss of smell and taste, severe or persistent cough as well as loss of appetite were also highly predictive. Likewise, Apra et al. [30] reported that anosmic or ageusic patients were more likely to be infected but suggested to prioritize RT-PCR tests in patients with cough. Mao et al. [27] also found that exposure history was an independent risk factor for SARS-CoV-2 infection. Fever is usually one of the most reported symptoms in COVID19 patients [37, 43]. In some studies, notably if performed in fever clinics [27], this symptom is so frequently reported $(>80 \%)$ in the global tested population that it does not help in the identification of COVID-19 patients. However, in a context of massive testing in a standard hospital, we showed that fever was reported by less than $20 \%$ of the symptomatic population. Our analyses revealed it to be the second most important factor associated with SARS-CoV-2 infection (behind loss of smell) at patient admission. It is worth noting that among all the aforementioned clinical signs, non-flu-like symptoms 


\begin{tabular}{|c|c|c|c|}
\hline \multicolumn{4}{|c|}{ The $\operatorname{COV}_{19}$-ID score } \\
\hline.$\tilde{z}$ & Smoker & $\begin{array}{c}\square \text { Yes } \\
\text { (-12.5 points) }\end{array}$ & $\begin{array}{c}\text { 口 No } \\
\text { (0points) }\end{array}$ \\
\hline 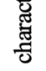 & Contact* COVID-19+ & $\begin{array}{c}\square \text { Yes } \\
\text { (10.5 points) }\end{array}$ & $\begin{array}{c}\square \text { No } \\
\text { (0 points) }\end{array}$ \\
\hline 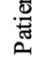 & Male sex & $\begin{array}{c}\square \text { Yes } \\
\text { (0.5 points) }\end{array}$ & $\begin{array}{c}\text { व No } \\
\text { (Opoints) }\end{array}$ \\
\hline \multirow{10}{*}{ 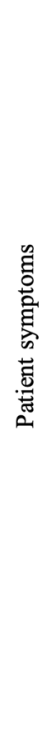 } & Loss of smell & $\begin{array}{c}\square \text { Yes } \\
\text { (35 points) }\end{array}$ & $\begin{array}{c}\square \text { No } \\
\text { (0 points) }\end{array}$ \\
\hline & Fever & $\begin{array}{c}\square \text { Yes } \\
\text { (19 points) }\end{array}$ & $\begin{array}{c}\square \text { No } \\
\text { (0 points) }\end{array}$ \\
\hline & Loss of taste & $\begin{array}{c}\square \text { Yes } \\
\text { (8 points) }\end{array}$ & $\begin{array}{c}\square \text { No } \\
\text { (0 points) }\end{array}$ \\
\hline & Cough & $\begin{array}{c}\text { (8 peints) } \\
\text { (8)e }\end{array}$ & $\begin{array}{c}\square \text { No } \\
\text { (O points) }\end{array}$ \\
\hline & Muscle stiffness & $\begin{array}{c}\square \text { Yes } \\
\text { (7.5 points) }\end{array}$ & $\begin{array}{c}\square \text { No } \\
\text { (0 points) }\end{array}$ \\
\hline & Back pain & $\begin{array}{c}\square \text { Yes } \\
\text { (6.5 points) }\end{array}$ & $\begin{array}{c}\square \text { No } \\
\text { (0 points) }\end{array}$ \\
\hline & Loss of appetite & $\begin{array}{c}\square \text { Yes } \\
\text { (5 points) }\end{array}$ & $\begin{array}{c}\square \text { No } \\
\text { (0 points) }\end{array}$ \\
\hline & Ear pain & $\begin{array}{c}\square \text { Yes } \\
\text { (-2 points) }\end{array}$ & $\begin{array}{c}\square \text { No } \\
\text { (O points) }\end{array}$ \\
\hline & Sore throat & $\begin{array}{c}\square \text { Yes } \\
(-2 \text { points) }\end{array}$ & $\begin{array}{c}\square \text { No } \\
\text { (O points) }\end{array}$ \\
\hline & Total & & points \\
\hline & COVID-19 Prediction & Total $\geq 14: P o$ & ive; Total $<14$ : Negative \\
\hline
\end{tabular}

Fig. 3 The $\mathrm{COV}_{19}-1 \mathrm{D}$ score

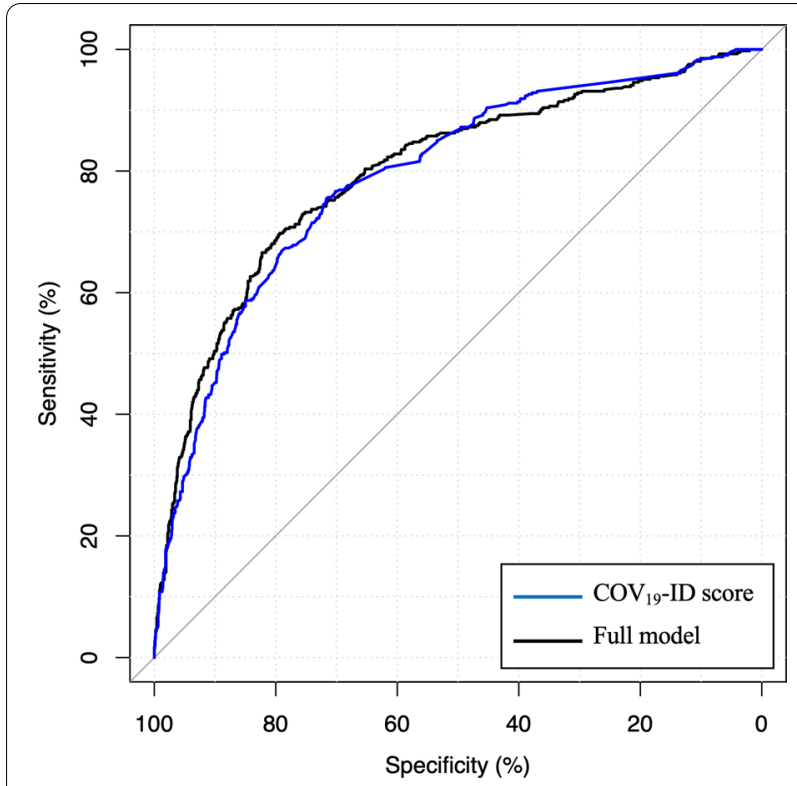

Fig. 4 The Receiver-Operating Characteristic analysis for the COV19-ID score and the full multivariable model such as loss of smell or loss of taste are often considered in the screening process for SARS-CoV-2 infection owing to their greater specificity [44-46].

Although excluded variables from our model were not predictive factors of COVID-19, they could be of great interest in the prediction of infection severity and should still be considered during the medical encounter. For instance, the association between diabetes and the severity/mortality of patients with COVID-19 is well documented $[47,48]$ although this medical condition is not a risk factor per se for SARS-CoV-2 infection. Similarly, identified protective factors for SARS-CoV-2 infection might become a risk factor for COVID-19 severity. In our study, smoking was more likely to be considered as a protective factor for RT-PCR positivity, but it nonetheless contributes to COVID-19 severity once the patient is infected [49-52].

As to the use of this model in clinical practice, we suggest keeping the patients blinded to the score at the time of symptoms screening. Otherwise, patients might be tempted to report symptoms that are either strongly related or not to SARS-CoV-2 infection thereby reducing the diagnostic performance of the $\mathrm{COV}_{19}$-ID score. Furthermore, patients are unfamiliar to medical jargon and the medical lexicon used to describe the symptoms needs to be adapted to the population understanding for appropriate data collection (e.g. anosmia = loss of smell; ageusia $=$ loss of taste, etc.). The strength of this score is its use at the time of admission. Solely based on patientself reported information, it requires no health personnel assistance. Compared to models using laboratory and/ or imaging data [53], this score is rapidly obtainable and does not require ancillary testing and/or patient radiation. Clinical uses of the $\mathrm{COV}_{19}$-ID score in a strained environment are large. Patients can be screened at admission and according to their score, directed to waiting areas planned for patients at low and high risk for SARS-CoV-2 infection thus preventing cross contamination [54]. Physicians or senior nurses can be appointed to patients at high risk areas thus optimizing resources. RTPCR tests for patients at high risk could be prioritized to reduce result delays and the burden on laboratory facilities. Patients for whom a first test is negative but with a high $\mathrm{COV}_{19}$-ID score can be scheduled for a second test to decrease false negative results. For the same purpose, RT-PCR tests (gold standard) could also be used instead of rapid antigenic tests when patients present a $\mathrm{COV}_{19}$-ID score above a certain threshold (e.g. $\geq 25$ points). Finally, a discriminating tool such as $\mathrm{COV}_{19}$-ID score has the potential to be incorporated in decision making algorithms used in telemedicine diagnostic strategies. 
Table 3 Model performance on the validation and test datasets (maximizing sensitivity and specificity)

\begin{tabular}{llll}
\hline & Validation dataset $\mathbf{( n = 1 8 0 6 )}$ & Test dataset $(\mathbf{n}=\mathbf{1 8 1 5})$ \\
\cline { 3 - 4 } & & Actual & Bootstrap (95\% Cl) \\
\hline True positive (TP) & 307 & 345 & 1001 \\
True negative (TN) & 1000 & 385 & $(80.6 \%-84.9 \%)$ \\
False positive (FP) & 399 & 84 & $(74.1 \%-74.3 \%)$ \\
False negative (FN) & 100 & $82.9 \%$ & $(80.4 \%-80.6 \%)$ \\
AUC & $79.1 \%$ & $74.2 \%$ & $(72.2 \%-72.3 \%)$ \\
Accuracy & $72.4 \%$ & $80.4 \%$ & $(47.2 \%-47.4 \%)$ \\
Sensitivity & $75.4 \%$ & $72.2 \%$ & $(92.3 \%-92.4 \%)$ \\
Specificity & $71.5 \%$ & $47.3 \%$ & $(2.90-2.91)$ \\
Positive Predictive Value (PPV) & $43.5 \%$ & $92.3 \%$ & $(0.26-0.27)$ \\
Negative Predictive Value (NPV) & $90.9 \%$ & 2.90 & $(0.59-0.60)$ \\
Positive likelihood ratio (LR+) & 2.64 & 0.27 & $(0.45-0.46)$ \\
Negative likelihood ratio (LR-) & 0.34 & 0.60 & 0.46 \\
F1 score & 0.55 & & \\
Mathews correlation coefficient (MCC) & 0.40 & & \\
\hline
\end{tabular}

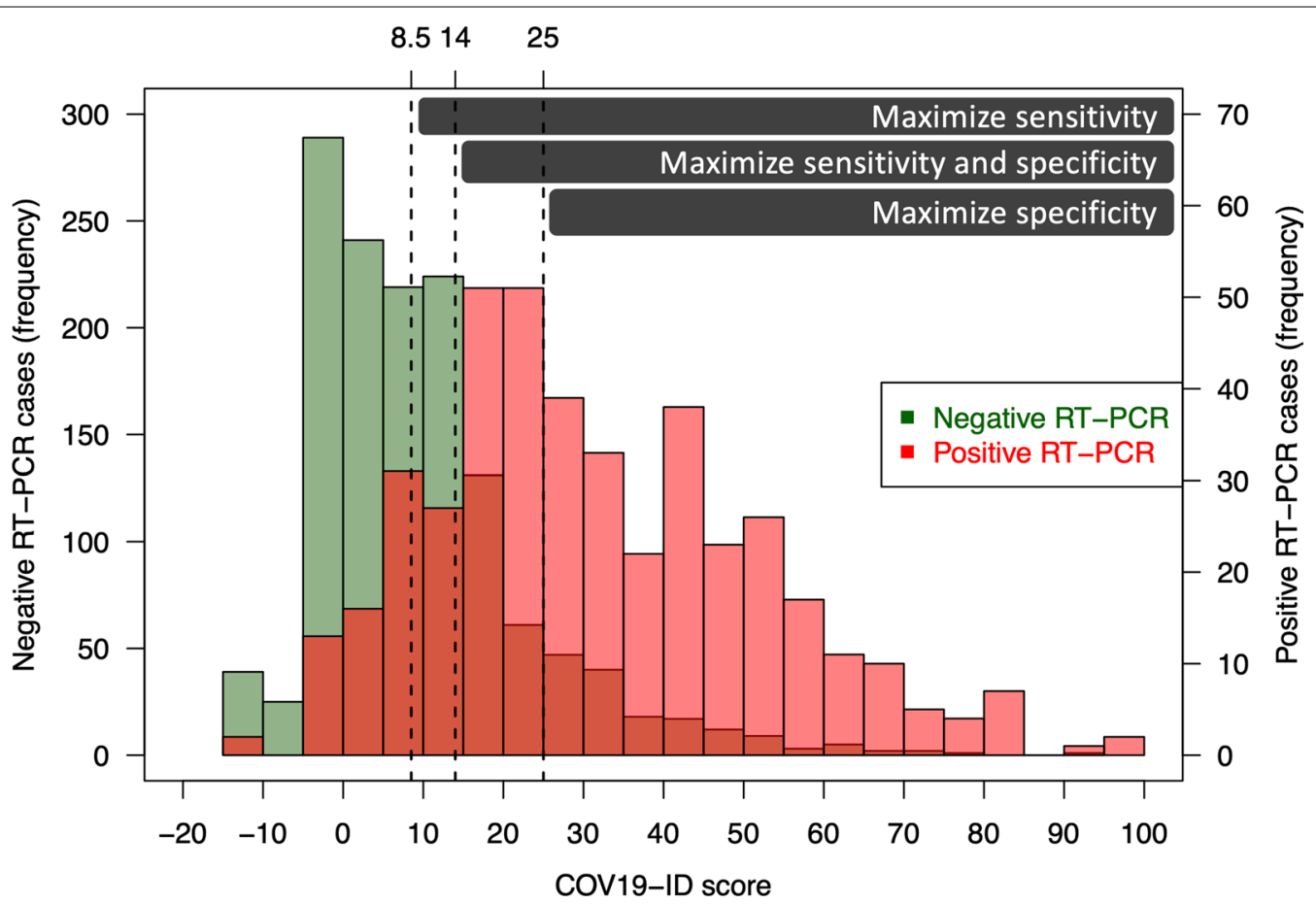

Fig. 5 Histograms of $\mathrm{COV}_{19}-\mathrm{ID}$ score in negative and positive RT-PCR cases

\section{Limitations}

This retrospective study has several limitations. First, the number of patients with confirmed SARS-CoV-2 infection may be underestimated notably because of the suboptimal sensitivity of RT-PCR tests. To this date, the RT-PCR test remains the gold standard for SARS-COV-2 detection, although specimen sampling was refined and test turnaround times shortened. Although first repeated tests for patients with symptoms aggravation were excluded from the database, a number of patients with false negative results could still remain in the datasets thereby weakening the analyses. Second, a non-negligible 
rate of incomplete forms was excluded from our database (5\%). However, the proportion of infected patients in the missing data was comparable to that of the studied dataset $(21.5 \%$ vs $22.9 \%)$ and should therefore not represent an important bias. Our sample size may be criticized compared to multicentric or nationwide studies, however, we built our analysis on real data, gathered at the time of specimen collection, without using imputation methods for missing values. Third, the $\mathrm{COV}_{19}$-ID score was constructed from a local and homogeneous population and therefore needs to be validated prospectively in other populations. Furthermore, due to the retrospective nature of our study, we could not evaluate the diagnostic performance of the $\mathrm{COV}_{19}$-ID score on new COVID-19 variants (that may present non-classical symptoms) and on a vaccinated population. Fourth, since the statistical model used in this study did not include all patient symptoms and clinical characteristics, confounding effects that are unaccounted for could still be at play. Although we did not observe a relevant difference in terms of time since symptoms onset between infected and non-infected patients, such a factor should be further analyzed to reduce false negative results. Fifth, the $\mathrm{COV}_{19}$-ID score was established on data collected between August and November where COVID-19 was the predominant circulating virus. Because the seasonality has a considerable impact on the onset of viral diseases other than COVID19; late spring, early summer and winter viruses such as the influenza virus may trigger flu like symptoms thus weakening the diagnostic performance of the $\mathrm{COV}_{19}$-ID score and increasing false positive rates (lower specificity). Further studies are therefore needed to estimate the impact of seasonality on the use of the $\mathrm{COV}_{19}$-ID score. Finally, the use of the $\mathrm{COV}_{19}$-ID score in a context of massive testing may be associated with a higher false negative rate at the time of RT-PCR testing (lower sensitivity) due to a higher proportion of infected patients that may not present the majority of COVID-19 predictive factors yet.

\section{Conclusions}

This study presented and validated a new screening tool (the $\mathrm{COV}_{19}$-ID score) for SARS-CoV-2 infection detection based on patients self-reported symptoms and medical history. This score has an acceptable diagnostic performance and might be useful in early triage of patients needing RT-PCR testing thus hopefully alleviating the burden on laboratories, emergency rooms, and wards.
Confidence Interval; TP: True positive; TN: True negative; FP: False positive; FN: False negative; PPV: Positive predictive value; NPV: Negative predictive value; LR+: Positive likelihood ratio; LR - : Negative likelihood ratio; MCC: Matthews correlation coefficient; RT-PCR: Real-time reverse transcription polymerase chain reaction; EUA: Emergency Use Authorization; FDA: Food and Drug Administration; CRF: Case report form; IQR: Interquartile range; VIF: Variance Inflation Factor; ROC: Receiver operating characteristic; AUC: Area under the curve; ENT: Ears Nose and Throat.

\section{Supplementary Information}

The online version contains supplementary material available at https://doi. org/10.1186/s12879-022-07164-1.

Additional file 1: Predicted probabilities of SARS-COV-2 infection compared to RT-PCR test results.

Additional file 2: Model performance on the test dataset using three different thresholds to maximize either sensitivity, specificity, or both.

\section{Acknowledgements}

The authors would like to thank each individual involved in patient care and/ or in data collection during the study period, without whom this investigation would have been impossible.

\section{Authors' contributions}

PDB conceived the study, supervised data collection and participated in manuscript redaction. $\mathrm{HB}$ performed the statistical analyses, prepared the figures and tables, and participated in manuscript redaction. OK and MR participated in manuscript redaction and data interpretation. PD, and FTB participated in data collection and manuscript editing. All authors read and approved the final manuscript.

\section{Funding}

This research received no specific grant from any funding agency in the public, commercial or not-for-profit sectors.

\section{Availability of data and materials}

The datasets used and/or analysed during the current study are available from the corresponding author on reasonable request.

\section{Declarations}

\section{Ethics approval and consent to participate}

This study was approved by the ethics committee of Geneva ("Commission Cantonale d'éthique de la recherche", CCER 2020-01742) and the need for informed written consent was waived owing to the urgent situation and the retrospective use of anonymized data. All methods were carried out in accordance with the relevant guidelines and regulations.

Consent for publication

Not applicable.

\section{Competing interests}

The authors declare nocompeting interests.

\section{Author details}

${ }^{1}$ Department of Emergency Medicine, La Tour Hospital, 1217 Geneva, Switzerland. ${ }^{2}$ Research Department, La Tour Hospital, 1217 Geneva, Switzerland. ${ }^{3}$ Department of Internal Medicine, La Tour Hospital and University of Geneva, 1217 Geneva, Switzerland.

Received: 21 April 2021 Accepted: 16 February 2022 Published online: 24 February 2022 


\section{References}

1. Fu L, Wang B, Yuan T, Chen X, Ao Y, Fitzpatrick T, et al. Clinical characteristics of coronavirus disease 2019 (COVID-19) in China: a systematic review and meta-analysis. J Infect. 2020;80(6):656-65.

2. Ferreira-Santos D, Maranhao P, Monteiro-Soares M. Covidcids Identifying common baseline clinical features of COVID-19: a scoping review. BM Open. 2020;10(9):e041079.

3. Corman VM, Landt O, Kaiser M, Molenkamp R, Meijer A, Chu DK, et al. Detection of 2019 novel coronavirus (2019-nCoV) by real-time RT-PCR. Euro Surveill. 2020. https://doi.org/10.2807/1560-7917.ES.2020.25.3.20000 45.

4. de Lusignan S, Dorward J, Correa A, Jones N, Akinyemi O, Amirthalingam G, et al. Risk factors for SARS-CoV-2 among patients in the Oxford Royal College of General Practitioners Research and Surveillance Centre primary care network: a cross-sectional study. Lancet Infect Dis. 2020;20:1034.

5. Bhargava A, Fukushima EA, Levine M, Zhao W, Tanveer F, Szpunar SM, et al. Predictors for severe COVID-19 infection. Clin Infect Dis. 2020;71:1962.

6. Chang MC, Park YK, Kim BO, Park D. Risk factors for disease progression in COVID-19 patients. BMC Infect Dis. 2020;20(1):445.

7. Chen R, Liang W, Jiang M, Guan W, Zhan C, Wang T, et al. Risk factors of fatal outcome in hospitalized subjects with coronavirus disease 2019 from a nationwide analysis in China. Chest. 2020;158:97.

8. Flook M, Jackson C, Vasileiou E, Simpson CR, Muckian MD, Agrawal U, et al. Informing the public health response to COVID-19: a systematic review of risk factors for disease, severity, and mortality. BMC Infect Dis. 2021;21(1):342

9. Galloway JB, Norton S, Barker RD, Brookes A, Carey I, Clarke BD, et al. A clinical risk score to identify patients with COVID-19 at high risk of critical care admission or death: an observational cohort study. J Infect. 2020;81(2):282-8

10. Gao J, Huang X, Gu H, Lou L, Xu Z. Predictive criteria of severe cases in COVID-19 patients of early stage: a retrospective observational study. J Clin Lab Anal. 2020; e23562.

11. Jain V, Yuan JM. Predictive symptoms and comorbidities for severe COVID-19 and intensive care unit admission: a systematic review and meta-analysis. Int J Public Health. 2020;65(5):533-46.

12. Li Q, Zhang J, Ling Y, Li W, Zhang X, Lu H, et al. A simple algorithm helps early identification of SARS-CoV-2 infection patients with severe progression tendency. Infection. 2020;48:577.

13. Liang M, He M, Tang J, He X, Liu Z, Feng S, et al. Novel risk scoring system for predicting acute respiratory distress syndrome among hospitalized patients with coronavirus disease 2019 in Wuhan, China. BMC Infect Dis. 2020;20(1):960

14. Liang W, Liang H, Ou L, Chen B, Chen A, Li C, et al. Development and validation of a clinical risk score to predict the occurrence of critical illness in hospitalized patients with COVID-19. JAMA Intern Med. 2020;180:1081.

15. Liu W, Tao ZW, Wang L, Yuan ML, Liu K, Zhou L, et al. Analysis of factors associated with disease outcomes in hospitalized patients with 2019 novel coronavirus disease. Chin Med J (Engl). 2020;133(9):1032-8.

16. Passamonti F, Cattaneo C, Arcaini L, Bruna R, Cavo M, Merli F, et al. Clinical characteristics and risk factors associated with COVID-19 severity in patients with haematological malignancies in Italy: a retrospective, multicentre, cohort study. Lancet Haematol. 2020;7:e737.

17. Schalekamp S, Huisman M, van Dijk RA, Boomsma MF, Freire Jorge PJ, de Boer WS, et al. Model-based prediction of critical illness in hospitalized patients with COVID-19. Radiology. 2020. https://doi.org/10.1148/radiol. 2020202723

18. Shang W, Dong J, Ren Y, Tian M, Li W, Hu J, et al. The value of clinical parameters in predicting the severity of COVID-19. J Med Virol. 2020;92:2188

19. Tong X, Xu X, Lv G, Wang H, Cheng A, Wang D, et al. Clinical characteristics and outcome of influenza virus infection among adults hospitalized with severe COVID-19: a retrospective cohort study from Wuhan, China. BMC Infect Dis. 2021;21(1):341

20. Wang Z, Wang Z. Identification of risk factors for in-hospital death of COVID - 19 pneumonia-lessions from the early outbreak. BMC Infect Dis. 2021;21(1):113.

21. Wei YY, Wang RR, Zhang DW, Tu YH, Chen CS, Ji S, et al. Risk factors for severe COVID-19: evidence from 167 hospitalized patients in Anhui, China. J Infect. 2020:81:e89.
22. Yi P, Yang X, Ding C, Chen Y, Xu K, Ni Q, et al. Risk factors and clinical features of deterioration in COVID-19 patients in Zhejiang, China: a single-centre, retrospective study. BMC Infect Dis. 2020;20(1):943.

23. Zeng Z, Wu C, Lin Z, Ye Y, Feng S, Fang Y, et al. Development and validation of a simple-to-use nomogram to predict the deterioration and survival of patients with COVID-19. BMC Infect Dis. 2021;21(1):356.

24. Zhang J, Yu M, Tong S, Liu LY, Tang LV. Predictive factors for disease progression in hospitalized patients with coronavirus disease 2019 in Wuhan, China. J Clin Virol. 2020;127:104392.

25. van Halem K, Bruyndonckx R, van der Hilst J, Cox J, Driesen P, Opsomer M, et al. Risk factors for mortality in hospitalized patients with COVID-19 at the start of the pandemic in Belgium: a retrospective cohort study. BMC Infect Dis. 2020;20(1):897.

26. Huang D, Wang T, Chen Z, Yang H, Yao R, Liang Z. A novel risk score to predict diagnosis with Coronavirus Disease 2019 (COVID-19) in suspected patients: a retrospective, multi-center, observational study. J Med Virol. 2020;92:2709.

27. Mao B, Liu Y, Chai YH, Jin XY, Lu HW, Yang JW, et al. Assessing risk factors for SARS-CoV-2 infection in patients presenting with symptoms in Shanghai, China: a multicentre, observational cohort study. Lancet Digit Health. 2020;2(6):e323-30.

28. Yu T, Cai S, Zheng Z, Cai X, Liu Y, Yin S, et al. Association between clinical manifestations and prognosis in patients with COVID-19. Clin Ther. 2020;42:964.

29. Abate BB, Kassie AM, Kassaw MW, Aragie TG, Masresha SA. Sex difference in coronavirus disease (COVID-19): a systematic review and meta-analysis. BMJ Open. 2020:10(10):e040129.

30. Apra C, Caucheteux C, Mensch A, Mansour J, Bernaux M, Dechartes A, et al. Predictive usefulness of PCR testing in different patterns of Covid-19 symptomatology - analysis of a French cohort of 12,810 outpatients. medRxiv. 2020

31. Menni C, Valdes AM, Freidin MB, Sudre CH, Nguyen LH, Drew DA, et al. Real-time tracking of self-reported symptoms to predict potential COVID19. Nat Med. 2020;26(7):1037-40.

32. Alcoba-Florez J, Gil-Campesino H, de Artola GD, Gonzalez-Montelongo R, Valenzuela-Fernandez A, Ciuffreda L, et al. Sensitivity of different RT-qPCR solutions for SARS-CoV-2 detection. Int J Infect Dis. 2020;99:190-2.

33. Fumagalli C, Rozzini R, Vannini M, Coccia F, Cesaroni G, Mazzeo F, et al. Clinical risk score to predict in-hospital mortality in COVID-19 patients: a retrospective cohort study. BMJ Open. 2020;10(9):e040729.

34. Luo H, Liu S, Wang Y, Phillips-Howard PA, Ju S, Yang Y, et al. Age differences in clinical features and outcomes in patients with COVID-19, Jiangsu, China: a retrospective, multicentre cohort study. BMJ Open. 2020;10(10):e039887.

35. Wang TY, Liu HL, Lin CY, Kuo FL, Yang PH, Yeh IJ. Emerging success against the COVID-19 pandemic: hospital surge capacity in Taiwan. Ann Emerg Med. 2020:76(3):374-6.

36. Zavascki AP, Gazzana MB, Bidart JP, P.S. F, A. G, Kawski CT, et al. Development of a predictive score for COVID-19 diagnosis based on demographics and symptoms in patients attended at a dedicated screening unit. medRxiv. 2020

37. Yang J, Zheng Y, Gou X, Pu K, Chen Z, Guo Q, et al. Prevalence of comorbidities and its effects in patients infected with SARS-CoV-2: a systematic review and meta-analysis. Int J Infect Dis. 2020;94:91-5.

38. Romero-Gameros CA, Colin-Martinez T, Waizel-Haiat S, Vargas-Ortega G, Ferat-Osorio E, Guerrero-Paz JA, et al. Diagnostic accuracy of symptoms as a diagnostic tool for SARS-CoV 2 infection: a cross-sectional study in a cohort of 2,173 patients. BMC Infect Dis. 2021:21(1):255

39. Bertran Recasens B, Martinez-Llorens JM, Rodriguez-Sevilla JJ, Rubio MA. Lack of dyspnea in patients with Covid-19: another neurological conundrum? Eur J Neurol. 2020;27(9):e40.

40. Nouri-Vaskeh M, Sharifi A, Khalili N, Zand R, Sharifi A. Dyspneic and non-dyspneic (silent) hypoxemia in COVID-19: possible neurological mechanism. Clin Neurol Neurosurg. 2020:198:106217.

41. Spechbach $H$, Jacquerioz F, Prendki V, Kaiser L, Smit M, Calmy A, et al. Network analysis of outpatients to identify predictive symptoms and combinations of symptoms associated with positive/negative SARSCoV-2 nasopharyngeal swabs. Front Med (Lausanne). 2021;8:685124.

42. Tajlil A, Ghaffari S, Pourafkari L, Mashayekhi S, Roshanravan N. Nicotine and smoking in the COVID-19 era. J Cardiovasc Thorac Res. 2020:12(2):136-9. 
43. Grant MC, Geoghegan L, Arbyn M, Mohammed Z, McGuinness L, Clarke $E L$, et al. The prevalence of symptoms in 24,410 adults infected by the novel coronavirus (SARS-CoV-2; COVID-19): a systematic review and meta-analysis of 148 studies from 9 countries. PLoS ONE. 2020;15(6):e0234765.

44. Menni C, Sudre CH, Steves CJ, Ourselin S, Spector TD. Quantifying additional COVID-19 symptoms will save lives. Lancet. 2020;395(10241):e107-8.

45. Spinato G, Fabbris C, Polesel J, Cazzador D, Borsetto D, Hopkins C, et al Alterations in smell or taste in mildly symptomatic outpatients with SARS-CoV-2 infection. JAMA. 2020;323(20):2089-90.

46. Peyrony O, Marbeuf-Gueye C, Truong V, Giroud M, Riviere C, Khenissi K, et al. Accuracy of emergency department clinical findings for diagnosis of coronavirus disease 2019. Ann Emerg Med. 2020.

47. Abdi A, Jalilian M, Sarbarzeh PA, Vlaisavljevic Z. Diabetes and COVID-19: A systematic review on the current evidences. Diabetes Res Clin Pract. 2020;166:108347.

48. Guan WJ, Ni ZY, Hu Y, Liang WH, Ou CQ, He JX, et al. clinical characteristics of coronavirus disease 2019 in China. N Engl J Med. 2020;382(18):1708-20.

49. Guo FR. Active smoking is associated with severity of coronavirus disease 2019 (COVID-19): an update of a meta-analysis. Tob Induc Dis. 2020;18:37.

50. Reddy RK, Charles WN, Sklavounos A, Dutt A, Seed PT, Khajuria A. The effect of smoking on COVID-19 severity: a systematic review and metaanalysis. J Med Virol. 2020;93:1045.

51. Vardavas Cl, Nikitara K. COVID-19 and smoking: a systematic review of the evidence. Tob Induc Dis. 2020;18:20

52. Adrish M, Chilimuri S, Mantri N, Sun H, Zahid M, Gongati S, et al. Association of smoking status with outcomes in hospitalised patients with COVID-19. BMJ Open Respir Res. 2020;7(1):e000716.

53. Fink N, Rueckel J, Kaestle S, Schwarze V, Gresser E, Hoppe B, et al. Evaluation of patients with respiratory infections during the first pandemic wave in Germany: characteristics of COVID-19 versus non-COVID-19 patients. BMC Infect Dis. 2021;21(1):167.

54. Lien WC, Wu JL, Tseng WP, Chow-In Ko P, Chen SY, Tsai MS, et al. Fight COVID-19 beyond the borders: emergency department patient diversion in Taiwan. Ann Emerg Med. 2020;75(6):785-7.

\section{Publisher's Note}

Springer Nature remains neutral with regard to jurisdictional claims in published maps and institutional affiliations.

Ready to submit your research? Choose BMC and benefit from:

- fast, convenient online submission

- thorough peer review by experienced researchers in your field

- rapid publication on acceptance

- support for research data, including large and complex data types

- gold Open Access which fosters wider collaboration and increased citations

- maximum visibility for your research: over $100 \mathrm{M}$ website views per year

At BMC, research is always in progress.

Learn more biomedcentral.com/submissions 